\title{
On Bodies and the Need to Appropriate Them
}

\author{
Antje Velsinger
}

In this essay, I would like to deal with the following questions:

Are citizens in western societies, early in the twenty-first century, actually the owners of their bodies?

If so, how do these citizens use this ownership?

Could ownership of one's body lead to a subversive, or even utopian, potential for escaping today's cultural requirement of body-optimization?

Throughout the ages, people have retained a fascination with designing and actively shaping bodies. Cultures have always provided a huge variety of tools to implement such modification. In Ancient Egypt, for example, people already used various techniques such as masquerading, tattooing and mummifying as ways to fashion bodies and to preserve them from inevitable decay. ${ }^{1}$ But although bodies have always been possible to modify, the question of who designs them-or which social group has the right to manipulate and rule over them-has always been answered differently, depending on the society of any given time or place.

\footnotetext{
A. Velsinger $(\bowtie)$

Graduate Program Performing Citizenship, HafenCity University Hamburg, Hamburg, Germany

e-mail: mail@antjevelsinger.com

(C) The Author(s) 2019

P. Hildebrandt et al. (eds.), Performing Citizenship, Performance Philosophy, https://doi.org/10.1007/978-3-319-97502-3_6
} 
When the Parliament of England passed the Habeas Corpus Act in 1679, for the first time in European history, a citizen suddenly owned the right to his or her body, at least to a minimal degree. Due to this law, which can be translated from Latin as 'you may have the body', a first form of ownership of one's body-an ownership in the subjunctive-was granted to citizens, in order to prevent their unlawful or arbitrary imprisonment. This redefined similar ideas from the Magna Carta of 1215 . Before the actual imposition of the Habeas Corpus Act, the king was the one who owned, and therefore ruled over, the bodies of all the subjects living in his kingdom.

Ever since that Act, bodily self-determination has been a key issue of citizen rights. According to the sociologist Jürgen Mackert, citizenship is considered to be a contract between governmental agents and the citizens of a state. This automatically implies a set of mutual rights and obligations. These rights and obligations are sufficiently defined that either party is likely to express indignation and take corrective action if the other fails to meet expectations. ${ }^{2}$ Through the enactment of the Habeas Corpus Act, ownership of the body became an integral part of this contract between the representatives of the state and the individual citizens: owning one's own body became a right of the individual citizen and thus formed the basis of all later additions to the concept of citizenship.

As a consequence of the Habeas Corpus Act, the king's former right to arbitrarily own his subjects' bodies suddenly disappeared in European constitutional monarchies and democracies. Since then, in most western societies, ruling over another person's body-which is the case during punishment or rehabilitation in detention-has been regarded as a violation. This new concept has led to the citizens' insistence on rightful and justifiable binding laws and an executive that adheres to legal procedures. Consequently, in all cases where bodily self-determination is ignored, such as in torture, wrongful imprisonment or other forms of physical violation, citizen rights are automatically ignored at the same time. Being a citizen in western societies implies being entitled to particular rights, and these rights include ownership of one's own body. Although, of course, being a citizen implies much more than the right to own one's body, ${ }^{3}$ one can say that the least being a citizen means is that it is only the individuals themselves who can own their own body.

When I speak about the body, I refer to a phenomenological concept of the body. According to the phenomenological philosopher MerleauPonty, the human body simultaneously lives out its existence in two ways; 
as an object and as a subject. ${ }^{4}$ As an object, the body is what we have, it is physical and expanding material. As a subject, the body is what we are, as our body, because we can only perceive the world through our physical senses. Consequently, we can state that it also becomes characterized as an agent that perceives and transmits the outside world. This perception of the world in turn depends on how we physically use our bodies. According to phenomenology, the body is our medium to have a world ${ }^{5}$ and-as our perception of the world depends on the actions we perform with our bodies-it is also our medium to actively create a world with the help of, and as a consequence of, bodily actions and practices. I will come back to this potential of the body to create the world through particular bodily use later on.

What consequences have the citizens of today's western society developed from their ownership? In the seventeenth century, ownership of one's body was still an endangered concept and rather referred to a passive form of property, without any need for particular activities. Yet today, in our contemporary western culture, we not only own, but rather possess, our bodies, which implies a very active use that is based on physical practices.

Since the Act of Habeas Corpus, a cultural shift has taken place from passively owning a body to actively possessing it. Today the body is something that is treated and thought about as something that can be designed and possessed by every individual. According to Michela Marzano, at the beginning of the twenty-first century, the body seems only acceptable if it is mastered and controlled by the individual. ${ }^{6}$ Exhibiting a controlled body has become an individual form of proof that one is in control of one's self. This is why the well-shaped and controlled body is the quintessence of social success, happiness and the degree of perfection the individual has reached.

What physical practices do the citizens of the beginning of the twentyfirst century utilize to actively possess and control their bodies? In the following, I will outline some examples of practices applied with the aim of controlling and possessing a body.

\section{The Fitness Industry}

In contrast to normal sports that aim at conditioning the body through physical activity, the fitness industry in the last ten years has developed new methods, such as $\mathrm{EMS}^{7}$ or HYPOXI, ${ }^{8}$ that require only modest physical 
activity to shape the body. By using electrical muscle stimulation (EMS) or low-pressure machines (HYPOXI) on very particular body parts, the body can be 'designed' in a very planned and specific way.

\section{Plastic Surgery}

While in past decades plastic surgery was an exclusive and expensive service that only very few people were able to use, today, it has become part of pop culture and can be considered a common method used to modify body shapes and manipulate ageing processes. ${ }^{?}$

\section{The Pharmaceutical Industry}

In today's society, bodily malfunction can be controlled extensively with the help of the pharmaceutical industry. The use of drugs is a widespread method that aims at alleviating physical suffering, such as pain, and also controlling psychosomatic disorders-for example, through heightening powers of concentration to decrease depression.

\section{The Use of Apps}

Digitalization has brought about an increasing number of apps that allow full body monitoring. ${ }^{10}$ These apps allow the user to control and work on individual bodily functions - such as heart rate, muscular movement, sleep patterns, and so on. What is different from the other methods described so far is that this method for full bodily monitoring affects issues of ownership of personal body information. As apps produce data that is stored online, the information provided by an individual becomes part of big data and can then also be used by external institutions and users.

The methods described above show that the 'design-ability' of a body in the beginning of the twenty-first century meets with both economic interests and a culture of self-optimization. The cultural urge to transform, develop and optimize the body in western culture changes also the notion of habeas corpus. The subjunctive of habeas corpus has shifted to an imperative; it is no longer 'you may have the body', but rather, 'possess your body and get the best out of it!' One might conclude that the citizens of today use the ownership of their bodies mainly for enhancement and self-optimization, which are the cornerstones of the current neoliberal ideology. 
At the same time, the concept of ownership of one's body becomes blurred. Today's citizens readily share the rights to their bodies with other players - such as app providers or the pharmaceutical industry, all of whom have an enormous economic interest in the control and possession of the body of every citizen. It is salient that these economic enterprises not only possess but even appropriate the body of every citizen, and at a speed that compromises the ability of individuals to realize or to be able to cope with this new outcome. So, are we experiencing a new cultural shift today, towards possessing, appropriating and controlling bodies? Are today's citizens therefore voluntarily running the risk of losing their rights to their own bodies again and, consequently, falling into a newly developed passivity and alienation from their own bodies?

When debating these issues around these questions, MerleauPonty's notion of the body as an agent ${ }^{11}$ contributes a helpful view. He considers the body to be an agent that creates a reality as it receives it. If the body is our medium to perceive the world, and this perception depends on actions we perform, then the body is a potential medium to actively create a world by applying or rejecting particular bodily actions and practices. Instead of just accepting-or perhaps not seeing-the unpleasant economic reality of being appropriated, or instead of confirming a neoliberal ideology of self-optimization, today's citizens would have the choice to critically rethink their particular form of ownership of their bodies.

The sociologist Robert Gugutzer regards the body as a societal phenomenon in two ways: as a product of society on the one hand, and as a producer of society on the other. ${ }^{12}$ The human body is a product of society in the sense that our handling, our knowledge, our feeling and our notions of the body are defined by societal structures, values, norms, technologies and systems of ideas. On the other hand, the human body is a producer of society because our living together, our social organization, is essentially affected by the physicality of socially acting individuals. Social reality results from social actions and outcomes, and social action always involves bodily action. Therefore, bodily (inter-)actions play a crucial part in the construction of social reality.

This interdependence of social reality, social action and bodily action allocates a very powerful role to everyone who is designing, possessing or appropriating bodies - in other words, a political role.

As an artist, I consider the appropriation of bodies as a potentially critical tool with which to create other forms of reality-realities that escape 
the ideology of self-optimization and control. Consequently, in the research I do within the frame of the graduate school 'Performing Citizenship', I investigate a contemporary approach to utopian bodies. In this context, I understand utopian bodies as bodies that experiment with a different approach to the neoliberal logic of self-optimization and control.

In the following, I will discuss three examples of body appropriation in the artistic field to show how the appropriation of a different body can be used as a tool to produce a different social reality.

\section{Paul Beatrix Preciado: Testo Junkie}

The first example is the pharmaceutical and physical experiment of Paul Beatriz Preciado, as documented in his book Testo Junkie. ${ }^{13}$ Paul Beatriz Preciado is a contemporary writer, philosopher and curator who focusses on topics relating to identity, gender, pornography and sexuality. Preciado was originally known as a female writer and identified as a lesbian. In 2014, he announced that he was 'transitioning' and, in 2015, he changed his name from Beatriz to Paul.

Ten years before that, in 2005, Preciado started an eight-month experiment with self-administered testosterone. Interestingly, Preciado did not consider himself a 'transgender', so the reason why he took testosterone was not that he felt the desire to become male. However, Preciado identifies with a group who declare themselves 'gender pirates' or 'gender hackers'. Gender hackers call themselves copyleft users, who consider sex hormones to be free and to open bio-codes whose use they believe shouldn't be regulated by the state or dictated by pharmaceutical companies. ${ }^{14}$

Consequently, without seeking medical monitoring, Preciado bought testogel from illegal sources and started his body experiment. While he was taking the drug, it was not only his physical bodily appearance that changed, but also his whole way of thinking, writing, feeling, moving, imagining and acting. His body became the place where all these changes were negotiated. By using testogel as a tool, Preciado appropriated a different body. With his experimental practice, documented in the book Testo Junkie, Preciado 'hacks into gender', simultaneously rejecting any regulation either by the state or by pharmaceutical companies who normally control gender changes. 
In an interview Preciado said, 'I also thought about the project as a kind of collective adventure, in a sense, because I'm thinking about the body, not even just my own, as this kind of a living political fiction.[...] We must manage to actually create some political alliance of minority bodies, to create a revolution together'. ${ }^{15}$ With the aid of testogel as a technique to appropriate a different body, the body of the artist becomes a container for physiological and political micro-mutations. The body qualifies as a container in which alternative drafts of a transitioning gender model come into being and into action. Coming back to habeas corpus, in Preciado's case, 'you may have the body' implies the right to decide on your gender by selfdetermined use of a drug. In Preciado's bodily self-determination, gender becomes something that can be freely appropriated by every citizen.

\section{Leonardo Selvaggio URME}

The second example of an artistic strategy to appropriate bodies is the project URME, created by the Chicago-based artist Leonardo Selvaggio, ${ }^{16}$ based on the appropriation of only one body part-namely, the face. Selvaggio is an interdisciplinary artist whose work examines the influence of technology on identity. In his recent work, he is engaged in the idea of considering identity as data that can be manipulated or even corrupted.

In his project, URME, Selvaggio develops alternative ways to use the human face in order to subvert new technological developments in the field of facial recognition. With the help of the new facial recognition app 'FindFace', any stranger needs only a photo of our face in order to get access to any information we have ever communicated via our social media profiles. ${ }^{17}$

In order to protect people from this new form of surveillance, Selvaggio is developing his own defence technologies. In his art project, URME SURVEILLANCE, he allows anyone to appropriate his face by wearing a photo-realistic, 3D-printed mask. When a person takes on the face of the artist - in the form of a mask - camera systems equipped with facial recognition software identify that person as Selvaggio, thus attributing all of their actions to the identity of the artist. With this strategy of appropriating someone else's face, people can hide and protect their own identity in surveyed areas. Further, they also actively contribute to designing a new persona, as their physical actions are linked to another person, in this case the artist. 
In the project URME, the appropriation of someone else's face produces an interesting malleability of identities. The shared face is subverting facial recognition systems because information cannot be read correctly; as a consequence, the data is connected to the wrong social media account.

Coming back to habeas corpus, the project URME Surveillance produces an interesting new form of malleable utopian body. In this case, 'you may have the body' implies the right to hide, confuse and rebuild the identity of a body. A group of people can share multiples of one reproduced individual body part, in order to create a new identity mapped out by their physical actions, so that economic and governmental surveillance loses overall power and is thus ridiculed.

\section{Antje Velsinger The Bodies We Are}

The third example is my own research project The Bodies We Are, which is located in the choreographic field. ${ }^{18}$ In the project The Bodies We Are, I work with the appropriation of movement and perception patterns of foreign bodies; in other words, bodies outside the realm of the performer's experience. Based on the assumption that the body is our medium through which we have a world, the appropriation of a foreign body offers a tool for the perception of the world from a different perspective.

In the first part of the research project, ${ }^{19}$ I asked three performers/ choreographers ${ }^{20}$ to select and bring images of bodies with which they do not identify. Interestingly, the majority of these images were images of marginalized or non-mainstream bodies: obese bodies, extremely muscular bodies, bodies involved in BDSM practice, ${ }^{21}$ anorexic bodies, extremely flexible yoga bodies, bodies using different kinds of prothesis, and so on. Starting from the thesis that a body is not a stable entity but consists of movement patterns, bodily perception and imagination, I was interested in the following questions:

What happens if the performers try to appropriate these bodies by speculating on and taking over their movement logics?

What happens to the performers themselves if they try to step out of their own bodily reality and jump into an unknown territory of a body totally different from their own? What happens in the process of appropriation? 
Let's assume the body is not a stable entity, but rather, a complex system in which particular movement and perception patterns, particular desires and imaginations interact with each other.

Let's assume everyone has a choice of plenty of potential bodies. Can anyone enter, or 'hack into', any bodily system, if he or she appropriates its movement patterns?

Let's do one experiment. Please go online and open the following homepage: http://www.yossiloloi.com/portfolio/fullbeauty-project. Now, please go to image 6/16. Let's assume this is one of our potential bodies that we want to appropriate. What kind of choreographic or performative strategies can be used to appropriate it?

If one considers this body to be a system, the performer first has to speculate and decide, what the characteristics are and which of them are significant. These decisions depend on the individual person who is doing the appropriating. Accordingly, the appropriation of a foreign body always implies a transfer process which then provokes a deviation from our particular individual experience.

A possible performative strategy to appropriate this body:

Movement: Concentrate on weight and volume while you move. Use every movement to perceive as much gravity, heaviness and volume of your body, as possible. Try to intensify this by using your imagination.

Flesh: Focus on the masses of flesh and how these masses are rubbing against each other while you move. Frequent actions are draping your flesh around you and therefore having to grab and pull at your flesh to rearrange it.

Pace: Move slowly.

Breath: Breath goes slowly and against the resistance of the flesh-you have to produce this physically.

Movement orientation: Movement is rather initiated from the centre, not the periphery. Movement motivation: You expose as much volume to the space around you as possible. Use of object: Use an object to drape your volume on it. The object will help you to expand even better in space.

If a person wants to enter into the system of this body-these 7 points might be helpful as one possible strategy of appropriation. Plenty of others, of course, are also tenable. The combination and interaction of these 
different characteristics will produce a system that will change how he or she perceives and constructs the body. Interestingly, entering into this foreign physicality will also change the imagination and desires of the person who is appropriating. Consequently, appropriating a foreign body means not only appropriating its physicality and movement patterns but, through its physicality, also appropriating its imagination, its visions and desires. The person, who is appropriating this body will experience that there exists a direct interrelation between bodies and what is imagined and desired.

Relating all this to the habeas corpus theme, it can be said that the project The Bodies We Are expands its scope from a singular law to its utopian plural. It does not merely say 'you may have the body', it goes far beyond that; it claims that it is possible to appropriate a variety of-even plenty of-bodies depending on your own interests and needs. Therefore, my thesis is this: If a concrete interrelation exists between the physical actions of a body, its individual desires and its particular environment, then the appropriation of foreign bodies also implies a utopian potential. Appropriating a body can be used as a tool to encounter and experience the not yet known. It can be used as a tool to allow change in the way we perceive our bodily and social reality. Consequently, the appropriation of a foreign body can be used as a vehicle to jump into different systems-to hijack, seize or capture foreign spaces and realms of actions, thoughts and visions.

My final look at the implications of habeas corpus-'you may have the body' - can be summarized as follows: As I have discussed above 'having a body' in the beginning of the twenty-first century meets with a culture of self-optimization, and the right to own one's body has shifted into an imperative of enhancement and control. However, when accepting the body as an agent that has the capacity to produce concrete realities, ownership of one's body could also lead to a subversive, or even utopian, potential for escaping today's cultural requirement of body-optimization. If we use the artistic field to shift from passively being appropriated to actively appropriating a body, we gain space for redefining bodily selfdetermination. If we consider the body a space for action that produces concrete realities, not only artists, but every citizen can use his or her body to produce concrete bodily realities - realities that not only aim at enhancement and control, but that are also open to include the foreign, the unknown, the scary, or the challenging to imagine. 


\section{Notes}

1. Cf. Pommerening (2007) 'Mumien, Mumifizierungstechnik und Totenkult im Alten Ägypten: eine chronologische Übersicht' In: Wieczorek, Alfried (Hrsg). Mumien. Der Traum vom ewigen Leben, pp. 71-88.

2. Mackert, Jürgen (2006) Staatsbürgerschaft. Eine Einfübrung, p. 18.

3. As Engin Isin puts it: 'critical studies of citizenship over the last two decades have taught us that what is important is not only that citizenship is a legal status but that it also involves practices of making citizens - social, political, cultural and symbolic'. But following this thesis, it has to be stated that the medium for taking part in all these social, political, cultural and practices is the body. Cf. Isin, Engin F. \& Nielsen, Greg M. (eds) (2008) Acts of Citizenship, p. 17f.

4. Cf. Merleau-Ponty, Maurice (2012) Phenomenology of Perception, trans. Donald Landes, p. 94.

5. Cf. Merleau-Ponty (2012, p. 147f).

6. Marzano, Michela (2013) Philosophie des Körpers, p. 24.

7. http://www.stern.de/gesundheit/fitness/sportarten/ems\%2D\%2D-elektrische-muskelstimulation-schwitzen-unter-strom-3524208.html, date accessed 28 August 2017.

8. http://www.designyourbody.com, date accessed 28 August 2017.

9. See, MTV series 'I Want a Famous Face', which documents how normal citizens are getting a 'famous face and body' through the use of plastic surgery, https://www.youtube.com/watch?v=H3TeYTTNdSs, date accessed 17 March 2018.

10. One example is Apple's 'Health' app that gathers information in four distinct categories: Activity, Sleep, Mindfulness and Nutrition. The app consolidates health data from an iPhone, Apple Watch and third-party apps that the individual uses, allowing the user-and the provider-to view all the information in one place. http://www.apple.com/uk/ios/health/, date accessed 28 August 2017.

11. Cf. Merleau-Ponty (2012, p. 74).

12. Gugutzer, Robert (2015) Soziologie des Körpers, p. $8 f$.

13. Preciado Beatriz (2013) Testo Junkie.

14. Preciado (2013, p. 55f).

15. http://www.theparisreview.org/blog/2013/12/04/pharmacopornography-an-interview-with-beatriz-preciado/, date accessed 28 August 2017.

16. For a full documentation of the project see, http://www.urmesurveillance.com, date accessed 28 August 2017.

17. https://www.theguardian.com/technology/2016/may/17/findfaceface-recognition-app-end-public-anonymity-vkontaktedate accessed 28 August 2017. 
18. For full documentation of the project, see: http://antjevelsinger.com/ arbeiten/thebodiesweare/, date accessed 28 August 2017.

19. The first part of the research project took place between 9 and 29 February 2017 at the choreographic centre of PACT Zollverein, in Essen, Germany.

20. The performers/choreographers involved in the collaboration were Juli Reinartz, Johanna Roggan \& Vania Rovisco. The fine artist Sophie Aigner was also part of the research team.

21. BDSM is a variety of often erotic practices or role-involving bondage, discipline, dominance and submission, sadomasochism, and other related interpersonal dynamics.

\section{REFERENCES}

Gugutzer, Robert. 2015. Soziologie des Körpers. Bielefeld: transcript.

http://antjevelsinger.com/arbeiten/thebodiesweare/. Accessed 28 Aug 2017.

http://www.designyourbody.com. Accessed 28 Aug 2017.

http://www.stern.de/gesundheit/fitness/sportarten/ems\%2D\%2D-elektrischemuskelstimulation-schwitzen-unter-strom-3524208.html. Accessed 28 Aug 2017.

http://www.theparisreview.org/blog/2013/12/04/pharmacopornography-aninterview-with-beatriz-preciado/. Accessed 28 Aug 2017.

http://www.urmesurveillance.com. Accessed 28 Aug 2017.

Isin, Engin F., and Greg M. Nielsen, eds. 2008. Acts of Citizenship. London: Zed Books.

Mackert, Jürgen. 2006. Staatsbürgerschaft. Eine Einfübrung. Wiesbaden: Verlag für Sozialwissenschaft.

Marzano, Michela. 2013. Philosophie des Körpers. Munich: Diederichs Verlag.

Merleau-Ponty, Maurice. 2012. Phenomenology of Perception. Trans. Donald Landes. London: Routledge.

Pommerening, Tanja. 2007. Mumien, Mumifizierungstechnik und Totenkult im Alten Ägypten: eine chronologische Übersicht. In Mumien - der Traum vom ewigen Leben: Begleitband zur Sonderausstellun, ed. Alfried Wieczorek. Mainz am Rhein: Zabern.

Preciado, Beatriz. 2013. Testo Junkie. Sex, Drugs, and Biopolitics in the Pharmacopornographic Era. New York: Feminist Press. 
Open Access This chapter is licensed under the terms of the Creative Commons Attribution 4.0 International License (http://creativecommons.org/licenses/ by $/ 4.0 /)$, which permits use, sharing, adaptation, distribution and reproduction in any medium or format, as long as you give appropriate credit to the original author(s) and the source, provide a link to the Creative Commons licence and indicate if changes were made.

The images or other third party material in this chapter are included in the chapter's Creative Commons licence, unless indicated otherwise in a credit line to the material. If material is not included in the chapter's Creative Commons licence and your intended use is not permitted by statutory regulation or exceeds the permitted use, you will need to obtain permission directly from the copyright holder.

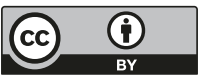

